\title{
Leadership and Administrative Skills:
}

\author{
A Panacea for Administrative Challenges in Schools
}

\author{
Peter Lameck Mduwile* \\ Educational Administration Program, School of \\ Postgraduate \\ Universitas Pendidikan Indonesia \\ Bandung, Indonesia \\ *mduwilepeter@upi.edu
}

\author{
Aan Komariah \\ Educational Administration Department, School of \\ Postgraduate Studies \\ Universitas Pendidikan Indonesia \\ Bandung, Indonesia
}

\begin{abstract}
This paper examined leadership and administrative skills and it emphasized on the meaning of leadership, leadership skills, the concept of efficiency, and administration for improving leadership and management in educational institutions. The topic under discussion suggests the need for leadership and administrative skills for every leader in educational institutions for effective leadership and management in educational institutions like secondary schools and universities. This insinuates that for the educational institutions to discern its aims and objectives, leadership and administrative skills must be put in. A qualitative approach was used by reviewing different literature. The results of the study show that teachers and principals are the ones who must have leadership and administrative skills to solve different administrative challenges which raising in the schools. To improve the academic quality of the school, student's performance in the class is highly influenced by the administrative and leadership skills of teachers and school principals.
\end{abstract}

Keywords-educational leadership, leadership styles, moral decay, school leadership

\section{INTRODUCTION}

Globally, qualities of leadership are typical to all organizations. Government leaders, health center leaders, business leaders, military leaders, and academic leaders generally convey to their respective organization's common features of vision, depth, and creativity. The most substantive aspect of school leaders is to help a school to fulfill the objectives and goals of the school or an organization [1-3]. Teaching and learning, supervision, instruction, educational programs, and assessment are the core concerns of schools and all this comprises education leadership. The study of leadership and administrative skills is very crucial nowadays because of rapid changes in the environment, organizations, society, and science and technology [4]. School principals and managers in school must have diverse skills to be committed to their roles as educational leaders. Educational administrators are portrayed as managers, principals and teachers are also portrayed as school leaders, therefore, community, students, and school boards demand good and effective leadership from school leaders and managers. Managers' and leaders' training programs also act as possible catalysts for the impact of the values, philosophies, and attitudes of the person to management. However, a study of school management growth and school leadership development literature over the past several decades indicates that, while knowing trust may be the desired outcome of several management and leadership development in schools [5-19].

\section{BACKGROUND}

All forms of student protests, lack of accountability for both school leaders and managers, cost-ineffectiveness, lack of fiscal integrity, and others are caused by poor leadership in Educational institutions like schools. And poor leadership is due to a lack of leadership and administrative skills on how to lead schools or educational institution. School leadership is an abstract and general idea that includes the worth of objectives and their influences of faculty and community. Any educational institution like schools, requires an effective leadership style to develop and have positive impacts on students and the community at large. The world comprises different people with different cultures, norms, values, and traditions which can affect educational institutions like schools. Most of the best educational institutions like schools have leaders who possess leadership and administrative skills which help them to provide effective leadership in their institutions or schools [8]. A leader is an integral part of different leadership styles where the main idea is based on situation, traits, and behavior. Again, other scholars argue that, leadership is about how to have an impact on and affect the interpretation of activities for subordinates, the preference of goals for the team or organization, the organization of work, things to do to accomplish the objectives, the motivation of followers to gain the objectives, the upkeep of cooperative relationships, and teamwork and enlistment of assist and cooperation from people outside the team or corporation [4].

All leadership styles which are known as a democratic, bureaucratic, transaction, transformation to mention a few, are playing a vital role in educational institutions or any corporate sectors where leadership is essential. According to Okorie [20] maintain that leadership and administrative skills are very 
crucial to any leader because those skills help and keep the school together, promote peace and harmony of the school, and encouraging teamwork. Leadership and administrative skills are very important like leadership itself because the development of the school, student performance, accomplishment of goals are contributed or affected by lack of leadership and administrative skills. In order school or any organization to develop, there is a need to put much emphasis on leadership skills because is the core essential for the development of any school. According to Ololube [21] asserts that lack of leadership and administrative skills lead to ineffective leadership which leads to underdevelopment of school and sometimes can defame the school missions and visions. Without leadership and administrative skills, even if there is plentiful of resources, the school will not develop because, to influence people, a leader needs to have certain skills that will help him/her to fulfil the desire.

\section{LITERATURE REVIEW}

School leadership is not different from other types of leadership outside of the education context. Leadership is the ability to influence [2-4,7,22-29]. It is very crucial in an educational context because poor leadership can lead to poor performance in the school and students and poor performance also can lead to poor leadership in the future since, the school is the place where future leaders are produced [30]. Likely in other sectors, leadership style depends on the situation of the schools and each leadership styles have the positive or negative impacts on the schools. Much research has conducted on leadership styles and leadership theories [29,31-36]. Leadership styles that are known today like laissez-faire, transformation, democratic, transaction, coach-style, strategic, bureaucratic, autocratic to mention a few, scholars grouped into three broad categories of democratic, liberal leadership or authoritarian leadership. Many of the leading ideas that have been applied to the educational environment in the twentieth century were rooted in Taylor's theories [9]. When work contributed to a deeper understanding of the motivational objectives and psychological needs of the individual, the emphasis of these leadership theories changed. Leadership style is how a leader has an impact on followers. For decades, leadership theories and leadership styles have been presented by different scholars on how to handle and manage the different organizational situations [3,37-42]. The different tactics which a leader uses to influence his followers to accomplish the organization's goals are referred to as leadership style. Those leadership styles can depend on the organizational situation, followers, aims, and goals of an organization, and this can be done democratically, in a laissezfaire way, in an affiliative way, in a servant way, in an autocratic way, in a coaching way, in a strategic way, in a transformational way, in a transactional way or in a bureaucratic way. As stated above, all this style is grouped into three broad categories which are democratic leadership, liberal leadership, or directive (Authoritarian) style.

\section{A. Directive Style (Authoritarian)}

In this style, a leader is the one who dominates and decide the management of the school or an organization. The power is invested to one person and the followers they will do what a leader will say. All decisions which are made in an organization can be decided or cancelled by the leader. One of the characteristics of the leader in this authoritarian style is, he/she is very strict to the followers, do not trust the followers or subordinates, always gives orders to his/her followers, usually provides punishment to his/her followers, and even reprimands to the followers public or privately. Followers' initiatives, visions, and strategies to the organization can be suppressed by the leader [3,25,41,43-48]. Though a leader focuses on the interests of an organization, his/her decision, the behaviour of reprimands followers public or privately can have negative impacts on his/her followers and to an organization. These impacts can affect follower's performance, can reduce follower's initiatives, responsibilities to the organization, and sometimes affect the psychological sphere of the subordinates $[3,9,38-42,49,50]$. A leader believes that he/she knows more than others or he/she smartest person in an organization.

".........autocratic leader as one who is very conscious of his position and has little trust or faith in the subordinates, he feels that pay is just a reward for work and it is only the reward which can motivate" [3].

The followers or subordinates usually have a little input or have no input at all. The approach which a leader uses to his followers is the command and control approach during decision making. Autocratic leadership and bureaucratic leadership falls under this leadership category [6]. This leadership style is rarely effective in an organization.

\section{B. Democratic Leadership Style}

A leadership style which emphasis on cooperation and teamwork with the subordinates or followers in the schools or any educational institution. During decision making of an organization, the followers or subordinates have a chance to provide input and are considered and appreciated by the leader. Again, before deciding anything, always a leader tends to ask the followers or subordinates like what do you think? what is your opinion? How can we solve this problem? And the followers usually give out their opinion, views, comments, or contribution on any matter which will be on the table for discussion [50-52]. By doing so, a leader creates trust, promote teamwork and cooperation from followers or subordinates [30]. Again it helps the followers to be creative, open-minded, and help them to develop by emphasizing self-awareness and being innovative. It is very effective in an organization or in schools. Democratic, laisser-faire, strategic, affiliative, coach-style fall in these leadership styles. According to Ugoani [53] there are four components of leadership known as KICS, whereby Kstand for Knowledge, I- stand for Intelligence, C-stand for Collaboration, and S-stand for Synergy. He asserted that every leader who wants to succeed in his/her organization or schools must have these four components which can drive the organization forward. To practice effective democratic leadership, strong vision, communication, commitment, self- 
awareness, creativity, emotional intelligence, and collaboration strongly required [9].

\section{Liberal Leadership Style}

In a liberal leadership style, a leader tends not to take any risk, and sometimes he/she doesn't show any initiatives. A leader in this style, usually allows his/her followers to be overflowed or drenched with the existing situation in an organization or any educational institution. In a liberal leadership style, a school leader usually puts trust in people or followers to know what to do by giving people chances to do what they can do for an organization. This style, emphasis on freedom of the followers or it give followers independence [29,40,54-57]. It is very effective in any organization when the followers are highly educated, self-motivated, in creative bodies where followers are independent and creative individuality in an organization [10,31,32,58]. Transformational and transaction leadership fall under this category and sometimes are effective and sometimes not in an organization, this since tradition scholars like Bass and others posits that transformation and transaction leadership modes tend to know who is an effective leader in an organization [7,53].

All leadership styles are good depending on the situation of an organization or school, types of activities, the follower's personality, and other factors like time and the goal want to be accomplished. However, in all styles, leaders are emphasized to have leadership and administrative skills which will help to push the organization forward to accomplish organizational goals.

\section{METHODOLOGY}

This study uses a qualitative research approach to examine leadership and administrative skills as the panacea to school challenges. The study reviewing three categories of leadership style and summarizing observations from several research papers. The design methods used were document analysis aimed to make a critical argument and to establish a broad framework for understanding leadership styles which can be a panacea for school challenges. Again, Bowen [59] posits that the process of reviewing electronic or printed documents to examine and interpret data in a systematic way is called the document analysis method. The study was done by combining the library research by reviewing various works of literature and documents through collecting data related research results. The first procedure was to identify and analyze leadership styles and how can solve administrative problems in schools. The second procedure was to assess the various kinds of literature and documents related to leadership needed to find a solution to the problem under study. The last procedure was to make a conclusion on the study and suggest solutions offered to the problems. Again recommendation was made for further research and improvement.

\section{RESUlTS}

Leadership and administrative skills are the instruments, practices, and capacities that an individual need to make progress at inspiring and coordinating others in schools or educational institutions. However, leadership skills include something more, the ability to help individuals develop in their own capacities, technics to help any organization to develop. It is frequently said that the greater part effective leaders are individuals who drive others to understand their own achievement in educational institutions. These leadership and administrative skills initiative will help school leaders to be focused on a dream, comprehends their jobs, shows uprightness, sets a model, comprehend the best approach to inspire the conduct of others, convey viably, ready to require dangers and prepared to proficient at critical thinking $[33,43]$.

The outlook of skills intended to beat the angle of properties, steady with which the idea of the capacities regarding authority relies upon the character qualities which are acquired. The angle of aptitudes makes conceivable administration to be educated. Scholars has proposed three groups of skills: technical, interpersonal or human skills and abstract thinking skills or conceptual skills.

Contingent upon leadership style which school leaders are utilized in schools, all skills are urgent in schools or educational institutions.

\section{DISCUSSION}

The development of science and technology has made the needs of different skills in different spheres of life. As in other sectors, the education sector wasn't left behind on this development, this makes that leadership styles that exist and has been exercised for decades in education context also need skills to solve different challenges in schools. Moreover, Anderson et al. [60] argues that leadership strategies are having relevant and crucial value since development in the science of technology and societies has affected work, motivations, behaviors, and attitudes in any organization like schools. Hence there is a need for every school leader (principals), school administrator (managers), and teachers to have leadership and administrative skills for the development of an organization and community in general [1]. Based on the leadership styles which are exercised in schools, the below are critical skills any leader and school administrator should have.

\section{A. Technical Skills}

As a school leader, to solve different problems in the school, should have technical skills which assume an appreciation of and proficiency in the methods, processes, procedures, and strategies of education. Also, the are non-instructional technical abilities inclusive of particular expertise in finance, accounting, scheduling, purchasing, building, and protection. In any school, leadership, and administrative roles, all concerning those roles it is very important to have technical skills because this skill helps to solve different challenges in 
schools. Creativity and innovation, IT literacy, writing skills fall under this category. School principals', managers and teachers need technical skills that will be a panacea for school challenges which schools are passing through.

\section{B. Human Skills}

Human competencies refer to the school leaders or administrator's potential to work correctly and efficaciously with others on one-to-one groundwork and in team settings. These skills are concerning how to build and work in teams, how to communicate with the followers without any problem. A leader or administrator requires well self-understanding and acceptance as properly as appreciation, empathy, and consideration for others [17]. Currently, most of the leadership styles emphasize on human skills aspect because are the core skills in leadership. Its expertise base consists of an understanding of and facility for leadership, personal motivation, attitudinal development, group dynamics, human needs, morale, conflict management, and the improvement of human resources. These skills seem to be very important to leadership, administrative, and supervisory roles in schools or any organization [61]. Regardless of the position, status, education status, or leadership style he/ she exercises, all leaders, administrators, and supervisors usually work for others, and usually, they use different skills to accomplish goals. Again, Ugoani [53] posits that:

"Knowledge is critical to leadership because there are different types of leadership and different situations require different kinds of knowledge, and the person possessing the knowledge demanded by a certain situation in most cases tends to become the best leader."

\section{Conceptual Skills}

Conceptual skills are conceptual capabilities and competencies that enable an individual to apprehend complex situations to advance innovative and successful solutions. In other words, it is an herbal genius that addresses hard scenarios with a progressive strategy. Conceptual skills include the school leader or administrator's potential to view the school, the district, and the instructional program as a whole. These competencies consist of the advantageous mapping of interdependence for each of the aspects of the faculty as an organization, the instructional application as an educational system, and the functioning of human organization. The improvement of conceptual abilities relies closely on a balanced emphasis on leadership and administrative theory, information of employer and human behavior, and educational philosophy [2]. Conceptual competencies are regarded as greater necessary to roles similarly up the organizational hierarchy. The principals, for example, can also not understand a lot about the technical aspects of teaching children with studying disabilities to examine however should be aware of how this piece of the puzzle suits and interacts with different elements of operating the school. These skills make a leader or an administrator effective in his/her organization or school [62]. School leader can be distinguished from others as follows;
School leaders or administrators must be capable to radically change their vision, intensity, and creativity from idiosyncratic or non-public meanings into goals, buildings, and approaches for the school. Ideas become programs, visions turn out to be goals and feel of dedication from others emerge as operating structures. Indeed, the leaders interpret traits of management into characteristics of the school as an agency. School leaders or administrators must furnish possibilities for others to journey their imaginative and prescient and experience of motive so that others come to share in their ownership. Again, should be able to speak their experience of imaginative and prescient through phrases and examples. They should use language and symbols which are very easy to be understood also which speak a sense of excitement, originality, and freshness.

\section{CONCLUSION}

Generally, based on this finding and discussion, in order leaders and administrators to be effective in their duties, to solve different problems which have been raising in educational institutions like student's demonstration, strikes, principals, teachers, and school's managers should have diversity leadership and administrative skills to reduce those problems. Most of the problems in schools are caused by a lack of leadership and administrative competencies to leaders and administrators. Technical skills, human skills, conceptual skills, and science and technology skills like IT literacy are very important to every school leader should have and practice. Likely in other sectors, education leaders must be creative and innovative to be effective in leadership and administrative roles [63]. If principals, teachers, managers, and non-staff members had these skills, many problems have been solved in an educational institution. Also, there must be open space for students to build a dialogue concerning different school matters which can affect students and the community at large.

\section{SUGGESTIONS}

School leaders, principals, teachers, managers, and administrators at every level should have diversity leadership and administrative skills to help students to learn in a good way to become good citizens and good future leaders because education is the tool to the success of an individual and the success of a society as a whole.

The government should provide leadership training, seminars, workshops, and conferences and support regularly to principals, teachers, and school leaders to increase morale, skills and to boost their ability on how to lead schools and educational institutions. Again, the government should provide essential books and other materials to students for reading to help students and prepare them to be good leaders in the future.

The government should appoint Principals, education leaders who had an experience, and who can lead the school in a good way. 
Students who possess different skills and abilities like leadership skills, the school and community should nurture them for the benefits of the school, community, and country at large for the future.

\section{REFERENCES}

[1] L.N.W. Morgan, The Influence of School Leadership Practices on Classroom Management, School Environment, and Academic Underperformance. Walden University; 2015.

[2] Bolden R, Leadership , Management and Organisational Development. Handb Leadersh Manag Dev. 2010;1-12.

[3] GO I and JE O, "Impact of Leadership Style on Organization Performance: A Critical Literature Review," Arab J Bus Manag Rev. vol. 54172, no. 10, pp. 2223-5833, 2015.

[4] J.L. Godwin, C.P. Neck and E.R. Godwin, An Intersection of Transformational Leadership and the Chicago Campaign Case: Dr. Martin Luther King, Jr. and Servant Leadership, 1, pp. 21-6, 2015.

[5] M. Schraeder, D.R. Self, M.H. Jordan and R. Portis, "The functions of management as mechanisms for fostering interpersonal trust," Advances in business research, vol. 5, no. 1, pp. 50-62, 2014.

[6] R. Mittal, Leadership Theory, 10, pp. 1-8, 2017.

[7] T.B. Wen, C.F.H. Theresa, B.W.Y. Kelana, R. Othman and O.R. Syed, "Leadership Styles in Influencing Employees' Job Performances," Int J Acad Res Bus Soc Sci., vol. 9, no. 9, pp. 55-65, 2019.

[8] A. Zeb, S. Ahmad and G. Saleem, "Leadership Effectiveness and Organizational Performance: Exploring Gaps in the Existing Literature," Bus Econ Rev., vol. 10, no. 1, pp. 95-106, 2018.

[9] T.J. Burnham, Principal and Teacher Perceptions of Principa Leadership Behaviors as It Relates to Teacher Evaluative Feedback and Recognition [Internet]. ProQuest LLC. University of South Carolina; 2016.

[10] I.G. Vaccaro, J.J.P. Jansen, F.A.J. van den Bosch and H.W. Volberda, "Management innovation and leadership: The moderating role of organizational size," J Manag Stud., vol. 49, no. 1, pp. 28-51, 2012.

[11] S. Rani and U.D. Prasad, "Impact of leadership styles on teacher effectiveness," JIMS8M J Indian Manag Strateg., vol. 22, no. 2, pp. 50, 2017.

[12] D.M. Johnson, Instructional Leadership and Academic Performance in Tennessee High Schools. 2006;

[13] K. Franklin, Examining the Impact of Leadership Styles on the Motivation of U.S. Teachers, 2016, pp. 1-144.

[14] D.M. Church, Leadership style and organizational growth: A correlational study. ProQuest Diss Theses, 2012, 127.

[15] F. Walter, "The development of effective leadership: Investigating the antecedents of charismatic and prevention-oriented leadership behaviors. October. 2007;(3415):1 to 252 .

[16] C. Desjardins, "The Leadership Productivity Model," J Appl Leadersh Manag., vol. 1, pp. 20-38, 2012

[17] C. Desjardins and M. Baker, "The Leadership Task Model," J Appl Leadersh Manag., vol. 2, pp. 17-39, 2013.

[18] P. Maier, "The relationship of organizational culture and leadership in the context of SBE organizations," J Appl Leadersh Manag., vol. 3, pp. $128-54,2014$

[19] A.N. IȘIK, "Ethical leadership and school effectiveness: The mediating roles of affective commitment and job satisfaction,” Int J Educ Leadersh Manag., vol. 8, no. 1, pp. 60, 2020

[20] N.C. Okorie, The organizational stting of Leadership,Theory into practice in Educational organization. Port Harcourt: Gibbon and Sons Press, 2010
[21] N.P. Ololube, Educational Management Planning and Supervision: Model for effective implementation. Owerri, Nigeria: Springfield Publishers, 2013.

[22] J.G. Canady, "Leadership advocacy, ethical negotiations, and resignations to high-stakes assessment: A pilgrimage,” Diss Abstr Int Sect A Humanit Soc Sci, vol. 80, no. (11-A(E), 2019.

[23] A.D. Woods, A Correlational Study of Leadership Indicators and Literacy Outcomes : Examining a State Adopted Leadership Assessment Model, 2014.

[24] D. Belias and A. Koustelios, "The Impact of Leadership and Change Management Strategy on Organizational Culture," Eur Sci Journal, ESJ, vol. 10, no. 7, pp. 451-70, 2014.

[25] J. Kolodziejczyk, "Leadership and Management in the Definitions of School Heads," Athens J Educ., vol. 2, no. 2, pp. 123-36, 2015

[26] P. Deputy, What is the theory behind educational leadership? Educational leadership continued, 2009.

[27] D. Elmuti, W. Minnis and M. Abebe, "Does education have a role in developing leadership skills?" Manag Decis., vol. 43, no. 7-8, pp. 101831, 2005.

[28] C.E. Uzohue, J.A. Yaya, and O.A. Akintayo, "A Review of Leadership Theories, Principles, Styles and their Relevance to Management of Health Science Libraries in Nigeria," J Educ Leadersh Policy, vol. 1, no. 1, pp. 17-26, 2016.

[29] J. Jabs, F.W. Brown and S. Bryant, "Do Transformational Leadership and Growth Mindset Impact Safety for Wilderness Work Crews?" Journal of Leadership and Management, vol. 2, no. 12, 2018.

[30] K.K. Shortridge, Principals' Leadership Styles and the Impact on Student Achievement. University of Maryland. University of Maryland, College Park; 2015.

[31] M. Madsen, Leadership and Management Theories Revisited. Work Pap. 4, 2001.

[32] M.K. Sharma and S. Jain, "Leadership management: Principles, models and theories," Global Journal of Management and Business Studies, vol. 3, no. 3, pp. 309-318, 2013.

[33] S. Eacott, "Educational leadership relationally: A theory and methodology for educational leadership, management and administration. Educational Leadership Relationally: A Theory and Methodology for Educational Leadership," Management and Administration, pp. 1-151, 2015.

[34] S.L. Qodriah, W. Hartati, and A. Karim, "Self-leadership and career success: Motivation of college lecturers," Journal of Leadership in Organizations, vol. 1, no. 2, 2019.

[35] M.O. Yusuf, U.D. Muhammed and A.O. Kazeem, "Management of Leadership Style: An Approach to Organizational Performance and Effectiveness in Nigeria," Int J Humanit Soc Sci Educ., vol. 1, no. 2, pp $17-29,2014$.

[36] M. Alvesson and A. Spicer, Theories of leadership. Metaphor We Lead By Underst Leadersh Real World, 13, pp. 8-30, 2010.

[37] S. Stone and F. Gandolfi, "Leadership, Leadership Styles, and Servant Leadership," J Manag Res., vol. 18, no. 4, 261-9, 2018.

[38] H.N. Nguyen, "The Impact of Leadership Behaviours and Organisational Culture on Knowledge Management Practices in Small and Medium Enterprises," Consult Psychol J Pract Res., vol. 3, 2009.

[39] L. Veliu, M. Manxhari, V. Demiri and L. Jahaj, "The Influence of Leadership Styles on Employee'S Performance," J Manag Soc Sci Vadyb J Manag., vol. 31, no. 231, pp. 59-69, 2017.

[40] K. Sandell, "Transformational Leadership, Engagement, and Performance: a New Perspective," MSc Thesis, Color State Univ., pp. 1 to 97,2012

[41] L. Ferry and T. Ahrens, "Leadership style and job satisfaction in higher education institutions," Int J Educ Manag., vol. 30, pp. 140-64, 2016.

[42] A.M. Shafiu, H.A. Manaf and S. Muslim, "The impact of leadership on organizational performance," Int J Recent Technol Eng., vol. 8, no. 3, pp. 7573-6, 2019 
[43] J. Olson, M. Shurden and R. Caines, "Academy of educational leadership journal," Acad Educ Leadersh J., vol. 5, no. 2, pp. 127, 2004.

[44] F. Abadi and D.H. Perkasa, "The Local and Expatriate Leadership Styles in the in Indonesian Companies: A Qualitative Finding," Journal of Leadership in Organizations, vol. 2, no. 1, 2020.

[45] J.M. Adams, "Principal Leadership Practices in High Poverty K-5 Model Schools in Oregon," Diss Abstr Int Sect A Humanit Soc Sci., vol. $210,2015$.

[46] D.G. DeSorbo, "Leadership styles," Director, vol. 2, no. 4, pp. 135-6, 1994.

[47] D. Hasbay and E. Altindag, "Factors That Affect The Performance Of Teachers Working In Secondary-Level Education," Acad Educ Leadersh J., vol. 22, no. 1, pp. 1-19, 2018.

[48] V.E. Dike, "Leadership and Management in the 21st Century Organizations: A Practical Approach," World J Soc Sci Res., vol. 2, no. 2, pp. 139, 2015.

[49] F.M. Barbosa, L.D.N. Gambi and M.C. Gerolamo, "Leadership and quality management - A correlational study between leadership models and quality management principles," Gest e Prod., vol. 24, no. 3, pp. 438-49, 2017.

[50] S.N. Amedome, "The Influence of Leadership on School Climate: a Case of Senior High Schools in Hohoe Municipality of Ghana," Acad Educ Leadersh J., vol. 22, no. 2, pp. 1-16, 2018.

[51] E.H. Al Khajeh, "Leadership styles on organizational performance," J Hum Reseources Manag Resources, pp. 1-10, 2018.

[52] K.E. Spooner, Leadership and Decision-Making Skills of High Poverty Elementary School Principals in an Era of Reduced Resources, 2015.

[53] J.J.N. Ugoani, "KICS: A Model of Motivational Leadership in Organizations," Indep J Manag Prod., vol. 6, no. 3, 2015.

[54] V.R. Krishnan, "Transformational leadership and personal outcomes: Empowerment as mediator," Leadersh Organ Dev J., vol. 33, no. 6, pp. 550-63, 2012.
[55] S.S. Chen, The effects of transformational leadership oF by. 2014 August.

[56] P. Mukhtar and P.H. Ali, "Leadership Effectiveness: an Analysis of Transformational Leadership and Organizational Commitment ( Studies at the State University of Jambi Province, vol. 18, no. 11, pp. 72-80, 2016.

[57] B.P. Hardy, Transformational leadership and perceived role breadth: Multi-level mediation of trust in leader and affective organizational commitment, May, 2019.

[58] U.Y. Eseryel, D. Bakker and D. Eseryel, "Information technology selfleadership and its influence on team level product and process innovation," Journal of Leadership and Management, vol. 2, pp. 95-109, 2014.

[59] G. Bowen, "Document Analysis as a Qualitative Research Methods," Qualitative Research Journal, vol. 9, no. 2, pp. 27-40, 2009.

[60] H.J. Anderson, J.E. Baur, J.A. Griffith, and M.R. Buckeley, "What works for you may not work for Me: Limitations of Presents leadership theories for the new generation," The Leadership Quarterly, vol. 28, no. 1, pp. 245-260, 2007.

[61] D.A. Amir, "The Effect of Servant Leadership on Organizational Citizenship Behavior: the Role of Trust in Leader As a Mediation and Perceived Organizational Support As a Moderation," J Leadersh Organ, vol. 1, no. 1, pp. 1-16, 2019.

[62] E.K.F. Cripe, "An Examination into the Underlying Factors that Promote the Effectiveness of the Most Successful Division I NCAA Women's Soccer Programs," University of St. Thomas, Minnesota, 2017.

[63] W. Abbas and I. Asghar, "The Role of Leadership in Organizational Change Relating the Successful Organizational change to Visionary and Innovative Leadership,” Industrial Engineering, 2010. 